\title{
Sujeito proativo, autonomia e novas tecnologias: desafios na construção do humano na pós-modernidade
}

\section{RESUMO}

A realidade social, econômica e tecnológica que vivenciamos impõe novos modos de viver e se perceber o mundo, suscitando uma nova concepção de humanidade. O sujeito proativo, individualizado em suas buscas, adquire a sensação de ser mais incompreendido, numa época em que suas ações são convertidas em megabits, facilitando o trânsito de pensamentos e ideias. Compreender as implicações do imaginário tecnológico que perpassa o tempo presente, conhecendo suas promessas de autonomia, permite vislumbrar as configurações de um cenário que alguns autores denominam de pós-modernidade. Cenário que coloca desafios para o profissional do mercado e para os gestores de pessoas, em meio à sociedade competitiva. Para discutir tais questões, este texto apresenta alguns pressupostos teóricos que podem fazer avançar os debates em torno da criação de uma sociedade mais justa e mais democrática.

\section{PALAVRAS-CHAVE}

Autonomia

Novas Tecnologias

Gestão de Pessoas

\section{ABSTRACT}

The social, economical and technological reality of the society we live in imposes new ways of living and perceiving the world and brings a new conception of humanity. The proactive subjects, alone in their search, develop a stronger feeling of being misunderstood in a time when their actions are converted into megabits, facilitating the exchange of thoughts and ideas. Understanding the implications of the technological imaginary existing at the present time and perceiving its promises of autonomy enable us to observe the setting of a scenario that some authors refer to as post-modernity. Such scenario poses challenges to marketing professionals and human resources managers within a competitive society. In order to discuss these issues, this text presents some theoretical assumptions that might move forward the debates about the development of a more fair and democratic society.

\section{KEY-WORDS}

Autonomy

New Technologies

Human Resources Management

\section{Robéria Nádia Araújo Nascimento}

Professora do Departamento de Comunicação Social da UEPB/PB/BR rnadia@terra.com.br

\section{Edileusa Regina Pena da Silva}

Professora do Departamento de Educação da UFMT/MT/BR pena.edileusaregina@gmail.com

\author{
Oluzimere Pena da Silva \\ Administradora de recursos materiais do Pólo Petroquímico de Camaçari \\ $B A / B R$ \\ upena2009@hotmail.com
}

0 ritmo acelerado e a simultaneidade dos acontecimentos parecem trazer como desafios para o mundo a tarefa emergente de viver continuamente o aqui e o agora, pois "o próximo instante é desconhecido". Essa emergência aprisionada no instante realça a sensação de viver um presente eterno, sem ontem nem amanhã, apenas o instante e o imediato. A ciência e a tecnologia se encarregaram de possibilitar essa alteração momentânea entre passado, presente e futuro e com isso hipervalorizaram o presente. Passado e futuro são convertidos em meras figuras de linguagem.

Numa análise precipitada e pessimista desta nova era, poderíamos pensar que o ser humano adquiriu um esgotamento físico e psíquico, um vazio interior, um 
tédio crônico. Tudo isso identificado como dispositivos inerentes a uma nova sociedade na qual a velocidade na circulação de informação é premente. E clicar um mouse não significa ser interativo, principalmente porque ainda nos falta a capacidade crítico-reflexiva para superar as questões das máquinas como meros objetos de consumo ou reprodução simbólica do cotidiano voltado totalmente ao imaginário tecnológico.

Por esse viés lógico-racional, importa sobremaneira imprimir funcionalidade e uso criativo aos aparelhos, saindo do conforto do banal, no qual os artefatos tecnológicos consagram-se como o supra-sumo da inteligência artificial. Os humanos vão a cada dia se sentindo menos capazes de compreender e operar tais dispositivos com as enxurradas de comandos, links, novidades virtuais que emergem no cotidiano.

Assim, independentemente de nossas condições físicas ou emocionais, parecemos estar em descompasso com o ritmo alucinante de um mundo que flui a megabits por segundo ${ }^{1}$. Onde o espaço está sendo superado pela velocidade do tempo, ante as novas tecnologias de informação que encurtam as distâncias e afastam as pessoas de um vínculo mais forte e mais sólido com o outro, o mais próximo, o vizinho, o familiar ou o outro ele mesmo, refletido no espelho em busca do encontro indivíduo-indivíduo.

Nesse sentido, urge compreender as razões que permeiam este descompasso social e criam uma nova concepção de humanidade, alterando os vínculos interpessoais e modificando a noção de autonomia que havíamos construído ao longo dos séculos XIX e XX.

\section{Do indivíduo ao sujeito proativo contemporâneo}

Para Roman (1998, p. 39), o aparecimento do indivíduo surge na modernidade com a libertação de várias amarras sociais, políticas e religiosas da sociedade tradicional e a invenção de uma nova figura do homem. Seguindo o seu pensamento, percebemos que "a autonomia do indivíduo é a grande promessa da modernidade, da emancipação moderna, sendo a liberdade concebida e compreendida como autonomia" (Roman, 1998, p. 39).

Assim, a libertação do indivíduo só pode efetuarse através de um modo de vida urbano, de um espaço onde o anonimato seja uma garantia. "Na cidade, o indivíduo está desligado dos laços de dependências, de hierarquias, sejam sociais ou familiares, em que cada um se situava. A cidade é o espaço em que cada pessoa é desconhecida para outra, mas onde, ao mesmo tempo, se abrem espaços fantásticos de liberdade" (Roman, 1998, p. 41).
No novo cenário mundial, é certo que para o mercado capitalista os indivíduos são associados a números, a valores monetários. Como diz o autor: "àquele que chega ao mercado, não se lhe pergunta quem é, qual a cor da sua pele, que idade tem, nem qual a sua posição na escala social, mas apenas se tem dinheiro" (Roman, 1998, p. 42).

Saindo da modernidade para um estágio mais avançado, comandado pelas novas tecnologias de informação, há a integração de vários modos de comunicação em uma rede interativa, agrupando, no mesmo sistema, as modalidades escrita, oral e audiovisual de comunicação humana. Com uma senha ou um código de acesso tem-se a impressão de liberdade e autonomia. Por outro lado, é curioso pensar como as máquinas, endeusadas por uma forte política de marketing, estão se consagrando supostamente superiores aos homens, devido à sofisticação de seus softwares e comandos técnicos especiais que ultrapassam a capacidade humana de digitalização.

\section{A ciência e a tecnologia se} encarregaram de possibilitar essa alteração momentânea entre passado, presente e futuro e com isso

\section{hipervalorizaram o presente. Passado e futuro são convertidos em meras figuras de linguagem.}

É claro que as palavras ditas acima estão carregadas de exagero e de ilusionismo. No entanto, foi essa a impressão que filmes como Matrix, A Senha ou a Rede nos transmitiram, popularizando o imaginário coletivo tecnológico e suscitando dúvidas quanto à nova era. Entretanto, o que nos parece, depois de passado o entusiasmo da novidade eletrônica, sem rosto e sem identidade, é que estamos cada vez mais solitários, indagando até que ponto o indivíduo pode ser sujeito de si num mundo onde a autonomia é supervalorizada. $\mathrm{O}$ fato de precisarmos urgentemente do outro que nos 
completa ou que nos intriga impõe uma dúvida essencial: em que medida a emancipação comunicacional dos sujeitos equivale a sua autonomia?

Indubitavelmente, houve uma transformação no comportamento dos sujeitos desta nova sociedade, tornando-se, por um lado, mais solitários, individuais e isolados. Hoje, para chegar ao coletivo, ao grupo, o homem necessita da máquina. Ficando, então, a relação social homem $x$ homem dependente da intervenção da máquina, ou seja, a relação passa a ser homem - máquina - homem. Assim, o indivíduo torna-se menos um sujeito participativo e mais indivíduo-egocêntrico, desvirtuando o existente potencial tecnológico que poderia ser utilizado para criar um sujeito-cidadão capaz de intervir na sua autoemancipação social.

Como proclamou Morin (1995), dessa forma a elevação dos níveis de vida pode estar ligada à degradação da qualidade da vida. "A multiplicação dos meios de comunicação pode estar legada ao empobrecimento das comunicações pessoais. $\mathrm{O}$ indivíduo pode ser simultaneamente autônomo e atomizado, rei e objeto, soberano de suas máquinas e manipulado/dominado por aquilo que domina" (Morin, 1995, p. 89).

Corroborando com Morin (1995), entendemos que o homem transformou a Terra, domesticou suas superfícies vegetais, tornou-se senhor de seus animais. Mas não é o senhor do mundo, nem mesmo da Terra, embora tenha sido capaz de cruzar mares, continentes. Esse novo homem, que realizou conquistas importantes, deve aprender a ser humano e a viver no planeta, a partilhar, a comunicar, a comungar. Este novo homem precisa aprender a não mais apenas ser de uma cultura, mas a ser terrestre, solidário, fraterno, termos semelhantes a utopias socialistas, mas que devem ser resgatados nesse estágio social avançado denominado de pós-modernidade.

Sob esta perspectiva, Morin enfatiza que a emancipação social depende da reconstrução do mundo, e para isso o novo homem requer: reaprender a finitude terrestre e renunciar ao falso infinito da onipotente técnica, da onipotência do espírito, de sua própria aspiração à onipotência, para se descobrir diante do verdadeiro infinito que é inomeável e inconcebível: "Seus poderes técnicos, seu pensamento, sua consciência devem doravantes ser destinados, não a dominar, mas a arrumar, melhorar, compreender" (Morin, 1995, p. 185).

O ritmo acelerado da pós-modernidade nos imprime a visão de um ser humano perdido nos emaranhados das tecnologias e sem contatos presenciais com o outro. Com isso, alguns valores humanos vão se dis- tanciando da vida citadina. Solidariedade, humanidade e felicidade parecem "deletados" do cotidiano. É imperativo e urgente que a humanidade volte seu olhar para o indivíduo como um ser inteiro. Também precisamos resgatar valores éticos e morais ligados à compaixão. E, nesse sentido, compaixão não é ter dó ou piedade do seu próximo, mas, sobremaneira, é sentir o sofrimento do outro para uma compreensão mais integral do todo complexo dos sistemas abertos:

Por outro lado, esta rotina alucinante nos embriaga, pela sua capacidade de nos imobilizar em suas teias gigantes e tridimensionais, altamente envolventes e hipnotizadoras, que quando nos acostumamos não queremos mais "abrir mão". Quem, hoje em dia, conseguiria viver sem todo o progresso tecnológico produzido pelo homem em toda sua evolução? Afinal, não queremos retroceder.

Saindo do virtual/imaginário, podemos desfrutar de um mundo mais real e, assim, quem sabe podemos pensar o homem, a máquina, o tempo e o espaço numa composição mais harmoniosa, capaz de inspirar o sentido da autonomia, que é transformar indivíduo em sujeito ativo para provocar mudanças no núcleo social. Para isso, o espaço virtual deve ser usado com inteligência e eficiência, porque o destino virtual ou real da nova sociedade em rede ainda é muito incerto para a maioria das pessoas. O pós-moderno ainda está engatinhando, exigindo reflexões constantes, nas quais os sujeitos seguem "desvelando" o obscuro.

\section{Alteridade e emancipação: uma reflexão necessária na sociedade tecnológica}

A alteridade que Morin nos ensina é formada por um pensamento de emancipação que recusa a diversidade cultural como uma "escolha de superioridades", mas um processo que crê na evolução intelectual e individual de todos os seres humanos; que não julga a aparência, centrando-se na "essência do ser".

Trata-se de uma lógica cognitiva que questiona a razão dominante em busca de uma nova inteligibilidade social. Nessa perspectiva, alteridade implica aprender que nosso planeta é uma casa comum onde habita a diversidade dos humanos, com suas inteirezas e ambivalências, para além das discussões ecológicas, antropológicas, históricas, educativas. À luz de Morin, a valorização ética do outro ocorre sob o signo da comunicação, que é capaz de promover idéias de reconstrução e de resistência dos sujeitos sociais. Como isso se torna possível no cotidiano tecnológico que permeia as nossas vidas e interfere nas nossas relações interpessoais? 
A internet, que reúne em si múltiplas ferramentas comunicacionais, pode propor caminhos para a formação de uma cultura humanista, apta a integrar saberes de ricas e diferentes tradições. Ao misturar as partes que se mesclam ao todo, pode se transformar num amplo espaço de debate, sugerindo intervenções positivas na configuração social. Como realizar essa proposta?

A partir de uma leitura crítica nas páginas disponibilizadas na rede, nos blogs jornalísticos, podemos criar um sujeito proativo e integrado, por intermédio do conhecimento de relatos e experiências que colaborem para novas conquistas coletivas. É o desconhecimento das expectativas do outro que coloca os sujeitos sociais no anonimato, tornando opaca a sua identidade. Pelos portais da internet, há inúmeras possibilidades para se exercer o denominado jornalismo cidadão, permitindo a democratização dos papéis dos jornalistas na esfera social. Através de um celular, por exemplo, diversas coberturas jornalísticas podem ser enriquecidas mediante o olhar de pessoas que habitam o anonimato. Assim, a emancipação discutida por Morin torna-se mais próxima da realidade de cada sujeito.

A alteridade moriniana pressupõe o reconhecimento das subjetividades para que as negligências pessoais que nos colocamos, os preconceitos injustificados que conservamos, produzidos "inconscientemente" para confundir nossos raciocínios, sejam convertidos na atitude de abertura sincera em relação ao outro. É isso que as novas tecnologias nos permitem pensar, uma vez que se apresentam como vetor de potencialidades capazes de reduzir as distâncias entre nossos desejos e suas formas de realização. Para além das ameaças à cidadania, das exclusões sociais, existe o lugar da esperança e do imaginário, onde cada ser, de qualquer credo e de qualquer cor, se reinventa. O inacabamento da obra de criação da vida significa vencer os estranhamentos, abrindo novas passagens que nos humanizam. A internet pode se tornar um canal para esse desejo de humanização e alteridade, uma vez que se configura como espaço de múltiplas vozes, constituindo uma nova ágora de debates e discussões.

Assim, a alteridade moriniana é um convite à interiorização e um desafio para o desvelar de nossa condição humana; capaz de inspirar a construção de um pensamento amplo e colaborativo. Todas as iniciativas e aplicações tecnológicas do cenário pós-moderno certamente têm suas implicações no processo de desenvolvimento humano e social, ilustrando a perspectiva colaborativa defendida por Morin.

As relações de trabalho, a estrutura empresarial e as formas de selecionar, gerenciar, controlar, armaze- nar, divulgar e transferir informação sofrem alterações, trazendo como consequências novas formas de relacionamento comercial e social, além de outros modos de atuação das empresas. Falar de mundo corporativo, hoje, significa relacionar emancipação e alteridade, pois a partir de seu progresso no mundo do trabalho os sujeitos adquirem sua dignidade e passam a exercer sua autonomia. Nessa perspectiva, estamos nos referindo também à cidadania planetária.

\section{Urge compreender as razões} que permeiam este descompasso social e criam uma nova concepção de humanidade, alterando os vínculos interpessoais e modificando a noção de autonomia que havíamos construído ao longo dos séculos XIX e XX.

Participar deste mercado transnacional não é somente estar receptivo às importações de bens e consumo alheios. É, antes, ser emissor, agente de transformação e de venda dos nossos produtos e serviços. Como bem explica Canclini (1995), existe grande diferença entre internacionalização e globalização. O primeiro termo significou "uma abertura das fronteiras geográficas de cada sociedade para incorporar bens materiais e simbólicos das outras", ao passo que o segundo "supõe uma interação funcional de atividades econômicas e culturais dispersas, bens e serviços gerados por um sistema com muitos centros, no qual é importante a velocidade com que se percorre o mundo do que as posições geográficas a partir das quais se está agindo" (Canclini, 1995, p. 17).

No entanto, o autor supracitado alerta que estes meios eletrônicos comuns entre as massas populares estão deslocando o desempenho da cidadania em direção às práticas de consumo, bem como estão sendo "estabelecidas outras maneiras de se informar, de en- 
tender as comunidades a que se pertence, de conceber e exercer os direitos" (Canclini, 1995, p.30). Neste sentido, as atividades econômicas, políticas e sociais pensadas como bem de consumo e as condições de alteridade dos sujeitos, conforme alerta Morin, exigem uma reformulação do pensamento sobre a comunicação, porque este acesso simultâneo aos bens materiais e simbólicos não está acoplado a um exercício global e pleno da cidadania.

Já Hardt e Negri (2001) fazem uma avaliação da realidade global e das possibilidades de uma democracia ainda desconhecida. Neste sentido, a nova era é denominada de Império, mas em oposição ao imperialismo, porque identifica uma feroz alteração nos conceitos que formam a própria base filosófica da política moderna, como soberania, nação e povo.

O conceito de Império também está focado no capitalismo informacional e nas singularidades dos sujeitos sociais. Envolve ainda a construção de um novo significado para o capitalismo global que é constituído pela comunicação, inteligência, competência e cooperação. Uma ordem mundial que não aceita limites nem fronteiras e tem como alicerce básico o uso eficaz da informação como principal bem de consumo.

Os autores supracitados também substituem o conceito de povo para Multidão, porque o povo é uno e a multidão não é unificada, pois é composta por um conjunto de singularidades. Como explicitam: "a multidão designa um sujeito social ativo, que age com base naquilo que as singularidades tem em comum" (Har$\mathrm{dt}$; Negri, 2001).

Hardt e Negri (2005) investem ainda em um novo conceito, - $o$ de Biopolítica -, caracterizado pela ação política voltada para a transformação e a libertação conduzidas pela multidão. O Biopolítico também não se limita ao trabalho assalariado nem a fenômenos econômicos, refere-se às capacidades criativas humanas em toda sua generalidade, "tendendo a envolver todos os aspectos da vida social, entre eles a comunicação, o conhecimento e os afetos" (Hardt; Negri, 2005, p. 141).

Buscando compreender a lógica da vida humana na civilização mediática avançada, Trivinho (2007) empenha-se em desvendar o fenômeno social-histórico e a reordenação do processo civilizatório, além de compreender os princípios teóricos da sociodromologia fenomenológica, inspirada na obra de Paul Virílio, denominando esta nova era como dromocracia cibercultural.

Assim, para o autor mencionado, é impossível tomar a comunicação instantânea como objeto de pen- samento sem levar em conta o que lhe permite a existência. Da mesma forma, constitui contra-senso estudar as reverberações da velocidade sem considerar a sua coloração mediática e cultural. "Numa palavra, ser veloz significa dominar as linguagens da tecnologia de ponta em seus desdobramentos contínuos" (Trivinho, 2007, p. 103).

Como explica, "a dromocracia cibercultural abrange, com precisão refletida, a fase mundial atual do capitalismo tardio. Integrando comunicação em rede, instantaneidade e cultura digital, ela se traduz, em outros termos, como o estirão mais avançado da civilização mediática em tempo real" (Trivinho, 2007, p. 21).

Agora que o século XX já exibe certo distanciamento, autores como Trivinho conseguem de forma satisfatória tecer uma análise mais coesa da realidade sociotecnológica, cadenciada pela comunicação, velocidade e cultura:

A comunicação e a velocidade acabaram por forjar uma experiência antropológica típica, hoje subsumida na reprodução universal do social, a saber, o glocal - nem exclusivamente global, nem inteiramente local, misto de ambos sem se reduzir a tais , tendência mediática de magnitude ainda pouco apreendida e investigada, que sintetiza e, ao mesmo tempo, ultrapassa as suas duas bases constitutivas, assim como, seus respectivos derivados, a globalização ou o globalismo (econômico ou cultural) e os regionalismo ou localismos (Trivinho, 2007, p. 20).

Em síntese, o seu pensamento defende:

A dromocracia é o reino da velocidade e se a cibercultura como categoria de época (substituta do conceito de sociedade) é o reino do interativo e do virtual, a dromocracia cibercultural equivale ao processo civilizatório longitudinal fundado e articulado pelo usufruto diuturno da velocidade digital em todos os setores da experiência humana, horizonte no qual e a partir do qual a união inextricável entre comunicação, vetor dromocrático e cultura realizada pelo processo aleatório, via mercado, da informação, virtualização e ciberespacialização como indexador prioritário da experiência do mundo (Trivinho, 2007, p.25).

Na verdade, nosso interesse neste artigo é desmitificar as ideias elaboradas aleatoriamente a respeito do poder midiático e sua influência nos fenômenos sociológicos da contemporaneidade. Especialmente, porque, com a internet, o processo informacional-comunicacional vem tomando novos contornos, inclusive interferindo na rotina jornalística das mídias tradicionais, das redes sociais e do prossumidor (termo criado por Alvin Toffler que significa o consumidor ativo, respon- 
dendo ao que lhe é oferecido e antecipando as tendências, pois, é ao mesmo tempo produtor e consumidor de objetos, ideias, informações.).

A sociedade hipermoderna passa, então, por uma fase confusa e paradoxal, diante de uma enxurrada de informação, imagens, novidades tecnológicas e outras imposições dos novos tempos, que atordoam os sujeitos com valores que mesclam o tradicional, o moderno, o inovador, o consumo, a individualidade, o ser e o ter. Nessa espécie de paraíso perdido, em que se buscam referenciais a todo o momento, este novo homem e estas novas formas sociais se alteram num tempo e espaço virtual de nulodimensionalidade, o que coloca em suspenso as noções de alteridade humana.

Este artigo centra-se, portanto, nas especificidades do processo comunicativo virtual e sua capacidade de gerar e transmitir informações pertinentes ao desenvolvimento intelectual e social, sem anular as condições de alteridade dos sujeitos. Ou seja, defendemos a ideia de que é possível falar em autonomia comunicacional e emancipação nos espaços virtuais. Logo, analisamos aqui a propagação e o envolvimento (interatividade/ conectividade) do público, que passa a ser denominado como agente transmissor da mensagem, pela sua capacidade de, ao mesmo tempo, ser produtor e receptor no sistema comunicacional, assumindo sua voz e sua autonomia nesse processo.

\section{Configuraçóes do virtual: o planejamento e a valorização dos recur- sos humanos nas organizações}

Numa rápida comparação entre o visual e o virtual temos uma tríade comum, mas que exerce funções diferentes dependendo do veículo que está projetando a imagem ou a informação, interferindo, assim, na produção de símbolos (Imagem); no domínio do imaginal (Reflexão); e, na produção de desejos/necessidades (Interação-Conectividade), elementos que, no nosso entender, compõem uma nova concepção de autonomia.

O imaginal é quase sempre muito real, podendo constituir-se como simbólico, dependendo da construção reflexiva e da criação imaginativa do indivíduo, que pode ou não desfocar a sua perspectiva em relação ao objeto de desejo, à informação ou à notícia. Então, criam-se novos modos de percepção, seja visual ou virtual e, assim, o indivíduo pode ofuscar os valores reais, transparentes, evidentes, permitindo que seja projetada a ilusão, o desejo, - o objeto da sua criação imaginativa (imaginário).

Diante destas elucidações, fazem-se necessários alguns esclarecimentos, que caracterizam uma rede de poder e de relações, formada por dois lados que ge- ram a comunicação, e esta se dá a partir de alguns fatores básicos. Elegemos os seguintes:

Positivos: incorporação, aceitação, identificação;

Possiveis Consequências: geram a conectividade; possibilita a reflexão-conhecimento, fazendo com que a virtualidade se transfigure no real (a força do poder midiático);

Negativos: resistência e rejeição;

Possíveis Consequências: Falta de acesso, falta de conhecimento técnico e informacional, questões pessoais/afinidade, financeiras, entre outras. Pode acontecer de se fantasiar imagens, informações e conhecimentos tão pulsantes e vivos, bem delineadas e moldadas, que parecem reais.

No âmbito do mercado, todas as pessoas ativas são dotadas de inteligências múltiplas e da capacidade de "intelegir" (ser apta para desenvolver percepções inteligentes de si e dos outros com quem interage) em qualquer situação. Só que os rótulos instituídos pelos dirigentes empresariais podem levar as pessoas a desacreditarem de suas habilidades e capacidades.

\section{À luz de Morin, a valorização ética do outro ocorre sob o signo da comunicação, que é capaz de promover idéias de reconstrução e de resistência dos sujeitos sociais. Como isso se torna possível no cotidiano tecnológico que permeia as nossas vidas e interfere nas nossas relações interpessoais?}

Por sua vez, essa atitude empresarial incoerente pode inibir as pessoas nas tomadas de decisões e em outras ações que exigem criatividade e ousadia, como arriscar, pensar, criar e reinventar novas formas de realizar determinadas tarefas ou no exercício de suas funções operacionais. Enfim, deixar jorrar, transbordar todo talento e criatividade no desenvolvimento de suas atividades profissionais. 
É preciso que se repense as novas tecnologias, levando em conta alguns pontos fundamentais para, enfim, se ter as consequências práticas para uma avaliação. São necessários a participação e compromisso de todos para a concretização dos objetivos tecnológicos de forma humanitária, pois só assim, poderemos consolidar o processo democrático-informacional e a formação do sujeito proativo.

Estabelecer objetivos, princípios, prever, atingir metas. Isto tudo norteará o processo de inovação e gestão das tecnologias. Só com uma estrutura solidificada os gestores saberão qual a melhor decisão a tomar operacional, financeira e economicamente. E desse modo possibilitar uma melhor alocação de recursos humanos em novos projetos ou ainda a prospecção em áreas de atuação comum, gerando uma maior sinergia no programa como um todo.

É preciso que os gestores percebam a empresa como espaço de construção do conhecimento, da inteligência e de desenvolvimento de habilidades profissionais. Os conhecimentos adquiridos geralmente conduzem o indivíduo a uma aprendizagem significativa, e o mais importante de tudo isso, - permite apreender o conhecimento e transformá-lo em referencial para novas aprendizagens e questionamentos.

Durante muito tempo pessoas foram tratadas como seres robóticos, mecanizados, que só serviam para fazer e executar. Porém, as organizações viram que é necessário mudar, pois, estão lidando com "seres humanos", com sentimentos e emoções.

Também as formas contemporâneas de produção não se limitam mais a fenômenos econômicos. Estão, sim, voltadas para todos os aspectos da vida social, principalmente ao que diz respeito à comunicação, conhecimento e os afetos, bem como não se sustentam mais apenas na produção de bens materiais, mas, essencialmente, na produção de bens imateriais e na execução de um trabalho imaterial constituído de ideias, valores morais, éticos e humanos diretamente ligados à vida social em sua totalidade.

Como esclarece Hardt e Negri (2005, p. 151), "o trabalho imaterial tornou-se hegemônico em termos qualitativos, tendo imposto uma tendência a outras formas de trabalho e à própria sociedade". Nesse cenário, então, percebemos a grande dificuldade do ser humano em lidar com seu semelhante. Em algumas organizações as pessoas ainda são vistas como um mero recurso (objeto) e a capacidade de enxergar o outro como um ser pensante com vontade e desejos, fará o diferencial da nova organização e dos gestores de pessoas. Em outras palavras, Hardt e Negri (2005, p. 151) assinalam:
[...] o trabalho imaterial encontra-se hoje na mesma posição em que estava o trabalho industrial há 150 anos, quando respondia apenas por uma pequena fração da produção global e se concentrava numa pequena parte do mundo, mas exercia hegemonia sobre todas as outras formas de produção. Assim como naquela fase todas as outras formas de trabalho e a própria sociedade tinham de se industrializar, hoje o trabalho e a sociedade têm de se informatizar, tornar-se inteligentes, comunicativos e afetivos.

Para que o mercado desenvolva uma noção humanizada de alteridade, os gestores de pessoas precisam potencializar as atitudes, valorizando cada vez mais as competências individuais. Além dos conhecimentos, atitudes e habilidades faz-se necessário levar em conta valores e emoções e, assim, compreender a influência do humano nas suas ações. Reconhecer a humanidade no ambiente social e organizacional é uma atitude promissora para exercitar a democracia, favorecendo a emancipação.

É fundamental planejar. O planejamento estratégico é uma necessidade para manter e aprimorar o nível de excelência de uma empresa, provocando modificações em pessoas, tecnologias e sistemas, buscando projetar a empresa em situações futuras desejadas, adaptando-se e ajustando-se ao ambiente.

O Planejamento Estratégico, por ser um instrumento gerencial que agrega e integra ideias no sentido de implementar esforços e mobilizar recursos de maneira coerente, é fundamental para repensar alguns pressupostos das empresas que queremos construir. Porém, a participação e o compromisso de todos são fundamentais para a concretização das diretrizes importantes, pois só assim poderemos consolidar um modelo de gestão participativa com foco não apenas nos resultados, mas nas pessoas, seres humanos envolvidos no processo.

Vimos que no processo de gestão, planejar é fundamental. Estabelecer objetivos, princípios, prever, atingir metas. Isto tudo norteará o processo de gestão da organização. Só com esses planos traçados, os gestores saberão qual a melhor decisão a tomar operacional, financeira e economicamente. E desse modo a possibilitar uma melhor alocação de recursos humanos em novos projetos ou ainda a prospecção em áreas de atuação comum, gerando uma maior sinergia no programa como um todo.

E o que dizer sobre um mercado de trabalho altamente competitivo? A formação de um profissional é um processo lento e delicado. Todo o trabalho e esforço despendido nesse processo não podem ser desper- 
diçados. Devendo ser valorizada constantemente a busca de atualização e aperfeiçoamento, conforme discutimos acima.

Diante do exposto, o grande desafio para o profissional de RH possivelmente será a implementação de ações, voltadas a ampliação de probabilidades que propiciem direito à integração laboral e social de profissionais maduros, bem como proporcionar a longevidade profissional e uma vida produtiva de qualidade, por meio do constante aperfeiçoamento humano, operacional e acadêmico.

Por assim dizer, a área de RH e as organizações precisam atuar de forma conjunta investindo em políticas de valorização dos seus funcionários, a fim de diminuir os efeitos negativos provenientes da demissão. A avaliação por competência traduz-se numa maneira eficaz de identificar pontos fortes e características do profissional e readaptá-lo a uma nova função. Com a experiência que o profissional já possui em outras áreas isso facilitaria o seu aproveitamento e a oportunidade de demonstrar novos conhecimentos, podendo ser aproveitado em diversas atividades. Esses projetos servem também para o profissional interagir e estar em contato com outras pessoas, revendo e aumentando suas redes de relacionamentos, pois, isso pode facilitar sua recolocação no mercado de trabalho.

Indubitavelmente desenvolver pessoas não significa apenas proporcionar-lhes conhecimentos e habilidades para o adequado desempenho de suas tarefas. Significa, especialmente, promover formação básica para que modifiquem antigos hábitos, bem como, auxiliar no desenvolvimento de novas posturas críticas diante da vida e de si mesmo. Além disso, o RH precisa primar pela capacitação dos seus colaboradores, imprimindo-lhes uma nova mentalidade de aprimoramento dos conhecimentos e de suas habilidades, bem como o incentivo na busca constante do aprender a ser e do fazer bem aquilo que se pretende na empresa, na sociedade, enfim; na vida real das pessoas.

\section{Considerações finais}

A busca pelo desenvolvimento profissional e pessoal fortalece a autoestima e a valorização do capital intelectual. Conhecimento, habilidade, disposição e amadurecimento são fundamentais para que o profissional faça a diferença e seja diferente, ocupando o seu espaço e tecendo as trilhas do seu futuro. Sendo assim, em sintonia com o mundo atual, onde as mudanças e os avanços tecnológicos ocorrem de maneira muito rápida, as pessoas necessitam preparação para a nova realidade de trabalho imposta pelo mercado hipermoderno. Quanto mais conhecimento, qualificação e aptidões possuir o profissional, melhor será para seu desenvolvimento.

A atuação da área de Recursos Humanos como elemento facilitador nas empresas contribuirá para a formação de novos profissionais, altamente qualificados, fomentando a busca pelo conhecimento e aumentando significativamente o capital intelectual da sociedade. Gerando assim subsídios para a construção de um patrimônio de valor incalculável para as organizações, a comunidade e o mundo, atenuando as desigualdades existentes, ajudando a criar um novo sujeito proativo capaz de ressignificar o espaço social.

\section{Enfrentar a complexidade do} admirável mundo novo pode significar digerir informações, selecionar, hierarquizar conteúdos, atribuir sentidos às relações individuais e coletivas.

Como falar de gestão de pessoas num mundo marcado pela impessoalidade de relações? Na era planetária e na convivência com o virtual, somos conduzidos a implantar um chip de subjetividade/humanidade, de modo semelhante ao personagem Neo de $\mathrm{Ma}$ trix, que recebeu dose excessiva de informações que mal podia compreender.

Sob essa perspectiva, hoje, para podermos viver, interagir e lidar com os outros, necessário se faz uma dose extra de condição humana, parafraseando Morin, pois necessário também se faz conviver com as diferenças, generalizações, abstrações e, por que não dizer, distrações da sociedade tecnológica, que ocupam nossas mentes e dividem espaço com nossas emoções. Enfrentar a complexidade do admirável mundo novo pode significar digerir informações, selecionar, hierarquizar conteúdos, atribuir sentidos às relações individuais e coletivas. Esta difícil tarefa não pertence às máquinas, mas aos cérebros dos seres humanos, a quem, sabiamente, foi confiada essa importante misSão $\square$ FAMECOS 


\section{REFERÊNCIAS}

ARENDT, Hannah. A condição humana. 10. ed. São Paulo: Forense Universitária, 2003.

BAUDRILLARD, Jean. Simulacros e Simulação. Trad. Maria João da Costa Pereira. Lisboa: Relógio d'Água, 1991. 205p.

BAUMANN, Zygmunt. O mal-estar da pós-modernidade. Rio de Janeiro: Jorge Zahar Editora, 1998. 272p.

BETH, Hanno; PROSS, Harry. Introducción a la ciência de la comunicación. Barcelona: Anthropos, 1990.

BLASS, Leila Maria da Silva. Nas interfaces do trabalho, emprego e lazer. Texto apresentado no XXVII Encontro Anual da ANPOCS, realizado em outubro de 2003. Caxambu - Minas Gerais, 2003.

CANCLINI, Néstor García. Consumidores e Cidadãos: conflitos multiculturais da globalização. Rio de Janeiro: UFRJ, 1995. 226p.

Culturas híbridas: estratégias para entrar e sair da modernidade. 2. ed. São Paulo: EDUSP, 1998. 387p.

CASTELLS, Manuel. A sociedade em rede: economia, sociedade e cultura. São Paulo: Paz e Terra, 1999. 618p.

DESSLER, Gary. Administração de recursos humanos. São Paulo: Prentice Hall, 2003.

DIEZ, Fernando. El discurso del trabajo en el siglo de las luces. Sociología del trabajo. Madrid, n. 42, Primavera 2001, p. 119-144.

DUTRA, Joel Souza. Gestão de pessoas: modelo, processos, tendências, perspectivas. São Paulo: Atlas, 2002.

FERREIRA. Daniela Assis Alves. Tecnologia: fator determinante no advento da sociedade da informação. Perspectiva da Informação. Belo Horizonte, v. 8, n.1, jan./ jun.2003, p. 4-11.

FLEUTY, Maria Tereza (Coord.). As pessoas na organização. São Paulo: Editora Gente, 2002.

GARDER, Howard; KORNHABER, Mindy; WAKE, Warren K. Inteligência: múltiplas perspectivas. Porto Alegre: ARTMED, 1998.

GIL, Antônio Carlos. Gestão de pessoas: enfoque nos papéis profissionais. São Paulo: Atlas. 2001

HARDT, Michael; NEGRI, Antonio. Império. Tradução de Berilo Vargas 3. ed. Rio de Janeiro; São Paulo: Editora Record, 2001. 504p.

Multidão: guerra e democracia na era do império. Tradução de Clovis Marques. 3. ed. Rio de Janeiro;
São Paulo: Editora Record, 2005. 532p. Revisão Técnica de: Giuseppe Cocco.

KUCINSKI, Bernardo. Jornalismo na era virtual: ensaios sobre o colapso da razão ética. São Paulo: Editora Fundação Perseu Abramo; Editora UNESP, 2005. 144p.

MORGAN, Gareth. Imagens da organização. São Paulo: Atlas, 2002. Cap. 2, p. 22.

MORIN, Edgar; KERN, Anne Brigitte. Terra-Pátria. 2. ed. Porto Alegre: Sulina, 1995. 192p.

MOSCOVICCI, Fila. Equipes dão certo: a multiplicação do talento humano. 2. ed. Rio de Janeiro: J. Olímpio, 1995.

PEIXOTO, Aguirre. Qualificação: sobram mais de 9,6 mil vagas. Jornal a Tarde, Salvador, 06 jul. 2008, Caderno de emprego. p.1.

RICCI, Juliana. Maturidade profissional é o caminho para as competências pessoais. Jornal A Tarde, Salvador, 27 jul. 2007. Caderno de Emprego e Negócios. p. 04. Disponível em: <carreiras.empregos.com.br/comu$\mathrm{n}$ i d a d e s / r h / a r t i g o s / 310102 maturidade_profissional.shtm - 34k>. Acesso em: 30 jan.2008.

ROMAN, Joel. Autonomia e vulnerabilidade do indivíduo moderno. In: MORIN, Edgar.; PRIGOGINE, Ilya. (Orgs.). A sociedade em busca de valores - para fugir à alternativa entre o ceticismo e o dogmatismo. Lisboa: Instituto Piaget, 1998, 39-49p.

SANTAELLA, Lucia. Comunicação e pesquisa: projetos para mestrado e doutorado. São Paulo: Hacker Editores, 2006. 216p.

TRIVINHO, Eugênio. A dromocracia cibercultural: lógica da vida humana na civilização mediática avançada. São Paulo: Paulus, 2007. 456p.

\section{NOTA}

${ }^{1} \mathrm{O}$ megabit por segundo \% Mbps or Mbit/s \% é uma unidade de transmissão de dados equivalente a 1.000 kilobits por segundo ou 1.000 .000 bits por segundo. É preciso ficar atento ao usar essas unidades para não confusão entre os kilobits de rede e os kilobytes usados em hardware - memórias e discos rígidos. Assim, lembramos que 1 byte corresponde a 8 bits, portanto KB representa 1024 bytes em memórias e discos rígidos, mas $1000 \mathrm{Kbps}$ representa 1000 bits em dispositivo de rede. 